\title{
Creating Learning Environments for Indigenous Students through Cultured-based Math Modules
}

\author{
Ru-Fen Yao \\ Graduate Institute of Math and Science Education, National Chia-Yi University, Taiwan
}

Copyright $(2016$ by authors, all rights reserved. Authors agree that this article remains permanently open access under the terms of the Creative Commons Attribution License 4.0 International License

\begin{abstract}
The main purposes of this one-year case study are to create learning environments for indigenous students through culture-based mathematics instructional modules, and what teachers' responds are in two tribes. The researcher leads sixteen in-service teachers and seven pre-service teachers to enter two indigenous tribes- "Cado" and "Jayama", and design culture-based math modules for indigenous students of tribal elementary schools. Through five stages of guidance, including "preparation and planning", "exploration and understanding", "reading and design", "comment and revision", and "practice and reflection", the participants work together to develop seven sets of culture-based math modules in total. Based on observation, interview, and analysis of related documents, it is shown that the implementation through culture-based mathematics instructional modules could motivate students' interest in learning math, and enhance their initiatives in the classroom. Hopefully, such cooperation between universities and local elementary schools will lead to improvement in the mathematics learning environments for the tribes.
\end{abstract}

Keywords Culture-based Modules, Indigenous Students, Mathematics Learning

\section{Introduction on Literature Review}

In Taiwan, many studies [1-2] have pointed out that the achievements of indigenous students are lower than that of the Hans.

In fact, many advanced countries around the world have embarked on the studies of improvement for indigenous mathematics education based on the culture and local knowledge [3-6]. And the rise of modern scientific philosophical thinking and constructivism, using the multi-culture viewpoints and indigenous worldview or indigenous knowledge to discuss and design teaching materials and methods applicable for indigenous students are the main trends of the current relevant studies [7].
Cobern [8] had pointed out that science teacher needs a set of curriculum allowing indigenous students coming from different cultures to learn the Western science, and this set of curriculum must be based on the identification of indigenous knowledge and worldview.

Many scholars $[2,6,9-10]$ also pointed out that there was a lack of cultural perspectives in the mathematics curriculum, and this was easy to cause the mathematical learning without continuity for indigenous children. This was an issue of conversion of mathematical curriculum - the indigenous children come from different cultural backgrounds, so the situation of mathematical learning without a "cultural comprehensiveness" won't be able to make them feel a "sense of intimacy" while using teaching materials, and further affected their attitude towards learning mathematics.

Therefore, how to use the same mathematical concept to design the mathematics curriculums which could effectively cope with cultural differences and the teaching methods accepted by both the indigenous and Han's children is imperative. Just as what Ji and Liu [2] suggested, the existing teaching contents could not meet with the traditional values of indigenous people; the existing teaching contents never considered the cultural features and needs of indigenous people, and the teaching methods also took the standards of lowland schools which could not meet the actual needs of mountain schools. It could be seen that no matter how many teaching materials or teaching methods referred to, the mathematics curriculums in Taiwan were unable to consider the issue of mutual transformation and harmony among different cultures.

For the perspective of ethno-mathematics [2], the mathematical knowledge should focus on the diversity and culture, thus, in order to integrate more thinking and communication ways of different cultures into mathematical learning, and make children be able to actually construct mathematical knowledge, the issues related to "mathematical knowledge and cultural context", "mathematical education and culture", etc. have already become the focus concerned by many researchers and mathematical educator. For example, there are some scholars who have devoted themselves to studying the mathematical activities of 
indigenous tribes, and there are also researchers who investigate how to design mathematics curriculum, prepare and select mathematical teaching materials, carry out mathematical instructions, and how to cultivate teacher equipped with multicultural literacy [11]. Some mathematics educators attempt to integrate the mathematical activities related to daily life experiences into the school's mathematical instructions [12-13], and proposed relevant projects of mathematical education.

The indigenous people in Taiwan actually have their special difference from the one of Han culture, and that the indigenous children have difficulties in mathematical learning is a common fact [1]. For the reform of mathematics education, to respect and understand the indigenous children and their original experiences and knowledge in mathematical activity, and then guide them to learn school math is the direction worth endeavor. However, in Taiwan, math teacher education and school math curriculum are always based on the consideration of mainstream culture, rather than the cultural differences between various indigenous tribes and the Han, therefore, investigating the feasible path of "developing culture-based mathematics instructional modules " in this research has a space worth exploring.

The " culture-based mathematics instructional modules " develop in this research refers to a series of mathematics learning activities which blends into the indigenous cultures, that is, considering the unique traditional cultures of indigenous tribes and the life experiences of tribal children, integrating the mathematics with cultures, guiding students to learn mathematical concepts and relevant skills, so as to embed the mathematical learning situation into the tribal cultural context, and guide students to dig out the mathematical connotations behind the indigenous cultures, and also recognize the indigenous cultures and learn relevant mathematical knowledge via this set of curriculum [14]. The researcher expects the development and practice of "culture-based mathematics instructional modules" can not only enable tribal children to recognize and appreciate their original cultures and traditions, but also make mathematical education come through the tribes.

\section{Purpose}

The main purposes of this article are to introduce how the researcher created learning environments for indigenous students through culture-based mathematics instructional modules, and what teachers' responds are in two tribes.

Based on this practical experience and reflections, then the researcher will attempt to explore the key steps and important elements of the "development of culture-based mathematics instructional modules" for the next project. It would be able to provide a reference for teachers who are interested in developing indigenous mathematical teaching materials to have certain procedures to follow.

It is expected that such experience and reflections could further improve the tribal mathematical teaching and enhance the mathematics learning quality of tribal school children.

\section{Research Design}

This is a one-year case study. The researcher adopts "qualitative research approach", and takes "designing culture-based mathematics instructional modules" as path to create math learning environments for indigenous students in two tribes, Cado and Jayama.

The researcher guides sixteen in-service teachers and seven pre-service teachers work together to design culture-based mathematics instructional modules which can blend into the indigenous culture for tribal school children.

The following paragraphs will describe two research sites and the major participants there, followed by the introduction of the main procedure of this study, and the data collection in this study.

\subsection{Participants and Research Fields}

The researcher has established a team named "Tribal Math Volunteers" in the beginning of this research. The highest goal of this team is to gather those who have passion for tribal service and are interested in math learning of tribal children. Sixteen in-service teachers and seven pre-service teachers participate in this team.

The researcher leads these volunteers to enter two indigenous tribes, Cado and Jayama, and designs culture-based math modules for indigenous students of tribal elementary schools. Cado is a Tribe of Bunun people in Nan-Tou County. Its outside contact and traffic are convenient, and it takes approximately 30 minutes to drive there from the urban area of Puli. Jayama is a beautiful agriculture-based tribe, and clustered of Tsou, Bunun, and Han people. It is inaccessible and takes nearly two hours to drive there from Chia-Yi city.

Teacher A in Cado is a female Bunun, she is in charge of the sixth grade, and has twenty-years of seniority. Teacher B in Jayama is the male Han people, he is in charge of the first grade of case school, and has taught for four years. Both of them voluntarily participate in this research. The most important task of Teacher $\mathrm{A}$ and $\mathrm{B}$ is to practice the culture-based mathematics instructional modules in their math classes.

\subsection{Research Procedure}

There are five stages of the major research process described as below:

1)"Preparation and planning": to seek the partner schools and assign works to the volunteer team.

2) "Exploration and understanding": to visit, explore and understand these two tribal cultures.

3) "Reading and design": to widely search and read the 
literature related to indigenous people including Tsou and Bunun, and to design culture-based mathematics instructional modules.

4) "Comment and revision": there are three channels to comment on the draft of culture-based mathematics instructional modules, including comments within the design team, comments of co-teachers, and comments of administrative staffs and all teachers of case school. Then the team would carry out the revisions for the draft of culture-based mathematics instructional modules according all comments.

5) "Practice and reflection": The co-teachers practice the modules in the case classes of tribal school, and the design team is responsible for the on-site observation, records and photographing. Then volunteers reflect on and revise the modules according to the results of practice.

\subsection{Data Collection}

Five major data is collected in this one-year case study to understand how the researcher created learning environments for indigenous students:

1) Observations and records of the "Tribal Math Volunteers" meetings. The whole process of meeting is videotaped and the video is transcribed into word files, and there are also summarized records for each meeting.

2) Comments and reflection sheets (for the design of culture-based math instructional modules) by volunteers. After the design teams receive (1) peer feedback (2) comments of co-teachers (3) comments of administrative staffs and teachers of case school, and (4) comments of another team, they have to fill out the sheets in groups. The sheet is mainly for the peer opinions, including with what they agree, what they need to amend, on what they disagree, and the statements of their reasons.

3) Questionnaire of "what I see" (for the process of development and practice of culture-based math instructional modules) by volunteers. It is filled out after completing the design of modules, every designer has to fill out one copy in order to understand what they have learned and what they have got, the difficulties and the assistances they need, and their impressions and suggestions in the process of design.

4) All draft of culture -based math modules designed by volunteers. Before the "Tribal Math Volunteers" meetings, the design teams would upload the partial contents of the model design to the researcher.

5) Observations and interviews in two tribes, including the tribal visits, classroom observation, interviews, sharing and discussions with the tribal elementary school teachers.

\section{Results and Findings}

\subsection{Culture-based Mathematics Instructional Modules}

Seven sets of "culture-based math instructional modules" are developed by the volunteers, including "The Adventure of Millets" (for Bunun people), "A Great Test For Bali and Abbus" (for Bunun people), "Three difficult problems of NENG-GAO Mountains" (for Bunun people), "The Full Moon Festival " (for Bunun people), and "The Hometown of Clouds" (for Bunun people) applicable for the higher grades students, and "Pasuya's First Experience in Ceremonies" (for Tsou people) and "Bali's First Experience" (for Bunun people) applicable for the lower grades students.

Each set contains textbooks, workbooks, and teacher's guideline. The name, mathematics concepts, and applicable subject/indigenous people of these seven culture-based math instructional modules are listed in Table 1, and some samples of these modules' covers are shown in Figure 1, followed by the introduction of three modules which are selected to teach in the classrooms of Teacher $\mathrm{A}$ and Teacher B.

Table 1. Introduction of seven culture-based math instructional modules

\begin{tabular}{|c|c|c|}
\hline Name of module & Math concepts & Applicable subject/ people \\
\hline The Adventure of Millets & Decimal Division & Sixth grade students / Bunun \\
\hline A Great Test For Bali and Abbus & Statistics & Sixth grade students / Bunun \\
\hline $\begin{array}{c}\text { Three difficult problems of NENG-GAO } \\
\text { Mountains }\end{array}$ & Polygon and Circle & Sixth grade students / Bunun \\
\hline $\begin{array}{c}\text { The Full Moon Festival } \\
\text { Hometown of Clouds }\end{array}$ & Circle & Sixth grade students / Bunun \\
\hline Pasuya's First Experience in Ceremonies & Statistics & Sixth grade students / Bunun \\
\hline Bali's First Experience & Geometry, Count and Statistics & First grade students / Bunun \\
\hline
\end{tabular}



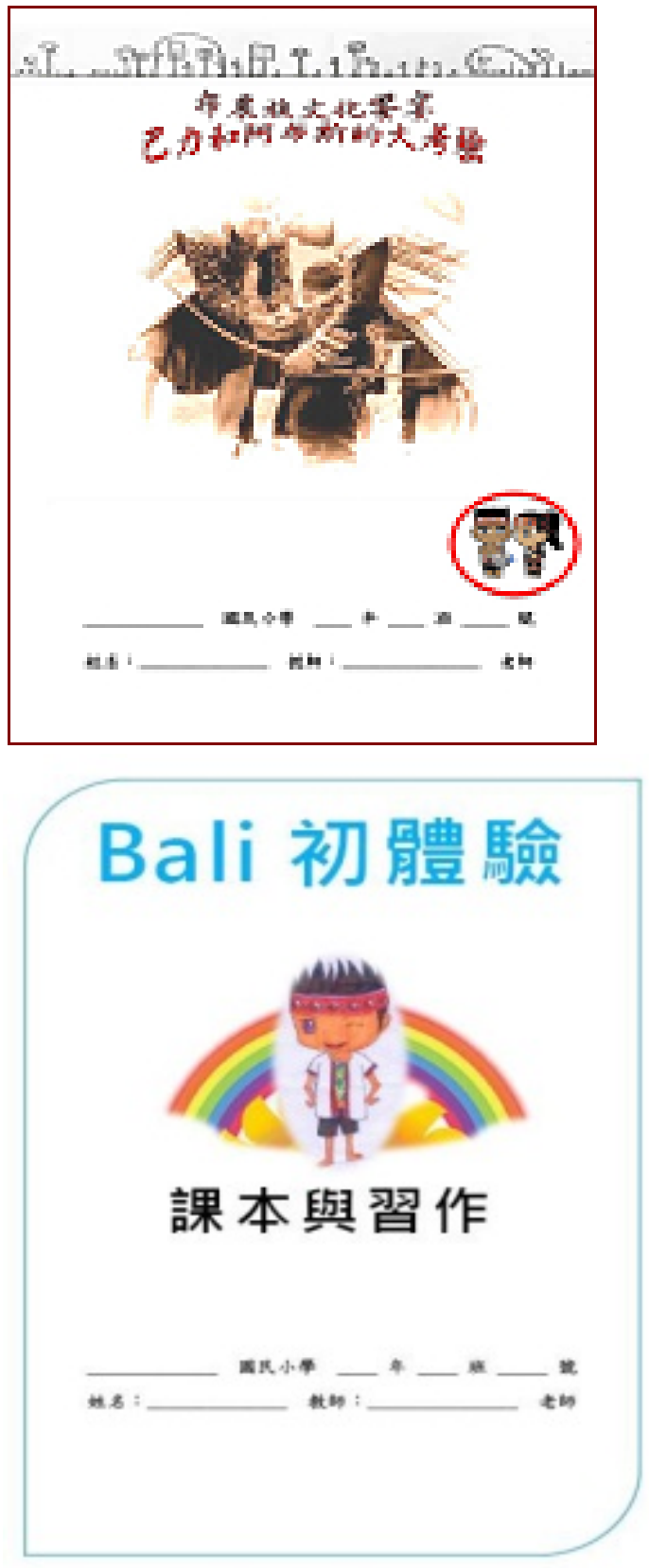

Figure 1. Samples of covers of culture-based math modules

\subsubsection{A Great Test for Bali and Abbus}

This module applies one of Bunun traditional ceremonies - "Ear-shooting festival" as its background, and with stories of Bali and Abbus during the ceremonies, students can be taught the chart concept within statistics unit. This module contains three activities such as "Beginning of dawn", "Ear-shooting festival", "Unlimited fate", it tries to enhance tribal students' interest in learning mathematics through the teaching of mathematics that has merged into the cultural situation.

\subsubsection{Three Difficult Problems of NENG-GAO Mountains}

This module is brought up from the myth of "Neng-Gao Mountain". Based on the story to throw up questions for

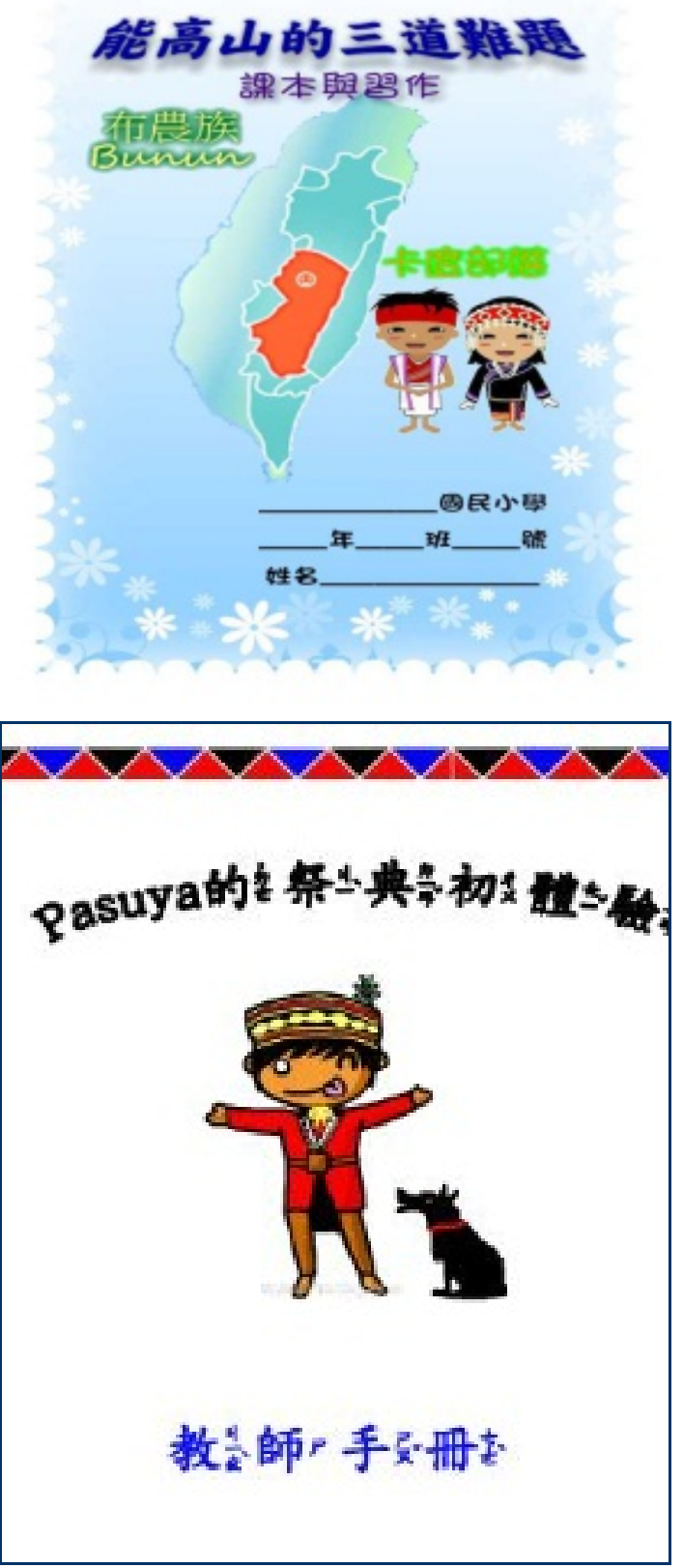

students to think and solve - Every teaching themes has been clasped with a problem that the Giant must face, enabling students to learn the related concepts of geometry by solving problems the Giant faces. This module contained three activities such as" Leader's pig and millet fields", "Test of flood", "Rising sun from cloud"; the designers wish that Bunun myth can make learning mathematics with fun and imagination, and through merging Bunun culture into mathematics instruction, students are going to further understand their own culture more.

\subsubsection{Bali's First Experience}

This module is based on a little boy Bali as the man character, and through Bunun unique calendar and the 
well-known ear-shooting festival it makes up a fascinating story, and integration with relevant mathematical concept to guide students on learning mathematics including "plane figure", "concept of space, "size of number", and" Statistics". This module contains four activities such as "Calendar: A huge secret treasure", "Watch out! Wild boars are on your side", "Ear-shooting festival ", and "War field intelligence".

\subsection{The Perceptions and Responses from the Cooperative Teachers}

Through interviews, observations, and analysis of relevant documents, the researcher make up four dimension "teachers' learning during the process of conducting modules", "teaching difficulties and needs during the process of conducting modules", "students' academic performance and reaction during the process of conducting modules ", and "teachers' suggestions for those who seek to design culture-based math instructional modules in the future" to present the perception and response of cooperative teachers A and $\mathrm{B}$.

\subsubsection{Teachers' Learning during the Process of Conducting Modules}

1) Through these cultured-based math modules, it is possible to find another way to teach math and to give students totally different learning experience. It is not necessary to follow textbooks to teach math.

2) Students play happily with a high degree of participation in these learning activities. During interaction with students, teachers could get 'energy' because of receiving a lot of feedbacks from students.

3) Teachers should follow students' experience in their life world to design learning activities and exercises. It will be easy to motivate students' interests in learning math.

\subsubsection{Teaching Difficulties and Needs during the Process of Conducting Modules}

1) The background of indigenous students is special, some of them try to make cultural heritage but also need to adapt to the mainstream culture. So sometimes there are doubts on their faces.

2) The tribes need more manpower. If manpower of teacher of tribal schools could be more sufficient, then teachers could put more dedication for lesson study. It will be more helpful of students' learning.

3) Teaching such modules is fun, but there is expectation and pressure of students' achievement from parents and school's administrative operations.

\subsubsection{Students' Academic Performance and Reaction}

1) Implementation through these picture books could motivate indigenous students' interest in learning math. During classes they obviously have interest and intentions in the classroom, and participated in the classes actively.

2) In the class of using these modules, the interaction between teachers and students is very good, and it is shown in the group discussions and exercises.

3) Teaching math through these modules could enhance the self-confidence of students to solve problems

4) Teaching math through these modules could lead students to experience that mathematics is not only a textbook knowledge but also can be applied in their daily lives.

5) Through these modules, students could learn their traditional culture, and also apply mathematical concepts to solve problems.

\subsubsection{Teachers' Suggestions}

It is very suitable to use these modules to teach math for indigenous students. But if it could be designed by tribal teachers themselves, teachers in tribes will have more accomplishment, and will be significant on affecting tribal children.

\subsection{Other Relevant Findings}

During the process of developing culture-based math instructional modules, the researcher finds: Since module designers have different "thickness" of cultural heritage, the orientations for design of " culture-based math instructional modules" are different; furthermore, due to the different administrative and teaching positions, the points of view of case school principals and teachers to look at the module connotation will be also different. Explanation is offered as following:

There are only three pre-service teacher volunteers that participate in this study with indigenous identity, the left volunteers are non-indigenous. Indigenous volunteers always think about the probable involved mathematical concepts through overall cultural context. But the rest of non-indigenous people are processing "seeking appropriate mathematical topics" and "understanding indigenous culture" at the same time, continuingly finding the possible intersection by their cross comparison.

Two principals are concerned about if taking about too many issues of culture in math classes will relatively squeeze the learning of mathematical contents. The principals repeatedly express and emphasize their doubts and worry in the meetings with the researcher. But the majority of case school teachers are glad to see such alternative (blend into the indigenous cultures) mathematical teaching materials, because they have profoundly experienced the low mathematical learning interests of indigenous children.

\section{Conclusions}

The indigenous tribes in Taiwan actually have their special differences from those of Han culture, and the preparation of mathematical teaching materials and the design of curriculums in Taiwan are always based on the 
mainstream culture, and seldom consider the cultural differences between various indigenous tribes and the Han.

The indigenous mathematical teaching materials can seldom be seen in the bookshops, therefore, the " culture-based math instructional modules " developed in this study attempts to provide tribal children the alternative mathematics learning environments from the two dimensions of teaching materials and learning contexts, so as to give them more choices, and enable them not only to learn basic mathematical knowledge and relevant skills, but also realize the utilities of mathematics and enjoy the beauty of mathematics, rather than limiting the mathematical learning passion of tribal children because of the environmental distress.

The researcher would attempt to explore the key steps and important connotations of the "development of culture-based math instructional modules " in the future based on the practical experience and reflections, and then to establish a model of developing culture-based math instructional modules, which is expected to provide a reference for the preparation of indigenous mathematical teaching materials, and further enhance the quality of mathematical learning contexts of tribal children.

\section{REFERENCES}

[1] Huang CS. Shorten the indigenous mathematical learning gap exploration and practice of activity and theory. Taipei: National Science Council; 2008.

[2] Ji, HY, Liu SC. Atayal children's learning world. Hualien Teachers College. 2000; 10: 65-100.

[3] Perry B, Howard P. Mathematics in Indigenous Context. Australian Primary Mathematics Classroom. 2008; 13(4): 4-9.
[4] Hurst C, Sparrow L. The mathematical needs of urban indigenous primary children: a western Australian snapshot. Mathematics Education Research Group of Australasia. 2010; 12: $272-279$.

[5] Grootenboer P, Sullivan P. Remote indigenous students' understandings of measurement. International Journal of Science and Mathematics Education. 2013; 11: 169-189.

[6] Jorgensen R., Grootenboer P, Sullivan P. Good learning = a good life: mathematics transformation in remote indigenous communities. Australian Journal of Social Issues. 2010; 45(1): 131-143.

[7] Snively G, Corsiglia J. Discovering indigenous science: Implications for science education. Science Education. 2001; 85(1): 6-34.

[8] Cobern WW. Worldview theory and conceptual change in science education. Science Education. 1996; 80: 579-610.

[9] Warren E, Devries E. Young Australian indigenous students: Engagement with mathematics in the early years. Australian Primary Mathematics Classroom. 2010; 15(1): 4-9.

[10] Bishop AJ. Mathematics Enculturation: A Cultural Perspective on Mathematics Education. Dordrecht: Kluwer Academic Publishers; 1991.

[11] Graham B. Mathematical Education and Aboriginal Children. Educational Studies in Mathematics. 1988; 19(2): 119-135.

[12] Ascher M. Ethnomathematics: A Multicultural View of Mathematical Ideas. Crawfordsville: Donnelley \& Sons Company; 1991.

[13] Nunes T. Ethnomathematics and Everyday Cognition. In: Grouws DA, editor. Handbook of Research on Mathematics Teaching and Learning. New York: Macmilian Publishing Company; 1992. p. 557-573.

[14] Yao RF. Tribal classrooms: Tribe-based mathematics learning and teacher education. Taipei: National Science Council; 2010. 